\title{
Correction to: Informing materials: drugs as tools for exploring cancer mechanisms and pathways
}

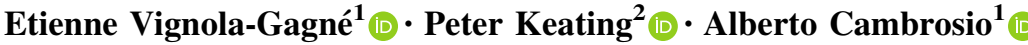

\section{Correction to: HPLS (2017) 39:10 https://doi.org/10.1007/s40656-017-0135-4}

The original version of this article unfortunately contained a mistake. Three entries are incorrect in the reference list. The corrected references are given below.

Davis, C. (2015). Drugs, cancer and end-of-life care: A case study of pharmaceuticalization? Social Science and Medicine, 131, 207-214.

Davis, C., \& Abraham, J. (2011). Desperately seeking cancer drugs: Explaining the emergence and outcomes of accelerated pharmaceutical regulation. Sociology of Health \& Illness, 33, 731-747.

Davis, C., \& Abraham, J. (2013). Unhealthy pharmaceutical regulation: Innovation, politics and promissory science. New York: Palgrave Macmillan.

The online version of the original article can be found under https://doi.org/10.1007/s40656-017-0135-4.

Etienne Vignola-Gagné

etiennevg@gmail.com

1 Department of Social Studies of Medicine, McGill University, 3647 Peel, Montreal, QC H3A 1X1, Canada

2 Department of History, University of Quebec at Montreal, Case Postale 8888, Succursale Centre-Ville, Montreal, QC H3C 3P8, Canada 